Published in final edited form as:

J Crit Care. 2017 August ; 40: 63-68. doi:10.1016/j.jcrc.2017.02.012.

\title{
The association between sodium fluctuations and mortality in surgical patients requiring intensive care
}

\author{
Dominic C. Marshall, BSc, MBBS ${ }^{a,{ }^{*}}$, Justin D. Salciccioli, AB, MA, MBBS ${ }^{b, c}$, Ross J. \\ Goodson, BSc ${ }^{d}$, Marco A. Pimentel, PhD ${ }^{e}$, Kristi Y. Sun, BSc ${ }^{d}$, Leo Anthony Celi, MD, MS, \\ MPH $^{\dagger}$, and Joseph Shalhoub, BSc, MBBS, FHEA, PhD, MEd, FRCS ${ }^{9}$ \\ aOxford University Clinical Academic Graduate School, John Radcliffe Hospital, Oxford, UK \\ ${ }^{b}$ Academic Foundation Program, Northeast Thames Foundation School, London, UK \\ 'Whipps Cross University Hospital, Barts Health NHS Trust, London, UK \\ IImperial College School of Medicine, Imperial College London, London, UK \\ eInstitute of Biomedical Engineering, Department of Engineering Science, University of Oxford, \\ Oxford, UK
}

'Beth Israel Deaconess Medical Centre, Division of Pulmonary, Critical Care, and Sleep Medicine, Boston, MA

gAcademic Section of Vascular Surgery, Department of Surgery and Cancer, Imperial College London, 4 North, Charing Cross Hospital, London, UK

\section{Abstract}

\begin{abstract}
Purpose-Serum sodium derangement is the most common electrolyte disturbance among patients admitted to intensive care. This study aims to validate the association between dysnatremia and serum sodium fluctuation with mortality in surgical intensive care patients.
\end{abstract}

Method-We performed a retrospective analysis of the Medical Information Mart for Intensive Care II database. Dysnatremia was defined as a sodium concentration outside physiologic range (135-145 mmol/L) and subjects were categorized by severity of dysnatremia and sodium fluctuation. Univariate and multivariable logistic regressions were used to test for associations between sodium fluctuations and mortality.

Results-We identified 8600 subjects, $39 \%$ of whom were female, with a median age of 66 years for analysis. Subjects with dysnatremia were more likely to be dead at 28 days (17\% vs $7 \% ; P<$. 001).

There was a significant association between sodium fluctuation and mortality at 28 days (adjusted odds ratio per $1 \mathrm{mmol} / \mathrm{L}$ change, 1.10 [95\% confidence interval, $1.08-1.12 ; P<.001]$ ), even in

\footnotetext{
${ }^{2}$ Financial support used for this study: Leo Anthony Celi is supported by National Institutes of Health Grant R01 EB001659. Marco A Pimentel is supported by the Research Councils UK (RCUK) Digital Economy Programme Grant EP/G036861/1.

${ }^{2}$ Conflict of interest: The authors report no conflict of interest.

"Corresponding author. dominic.marshall@medsci.ox.ac.uk (D.C. Marshall).
} 
patients who remained normotremic during their intensive care unit stay (1.12 [95\% confidence interval, $1.09-1.16 ; P<.001])$

Conclusions-This observational study validates previous findings of an association between serum sodium fluctuations and mortality in surgical intensive care patients. This association was also present in subjects who remained normonatremic throughout their intensive care unit admission.

\section{Keywords}

Electrolyte disturbances; Sodium; Mortality; Surgery; Dysnatremia

\section{Introduction}

Sodium plays an important role as the predominant extracellular cation found in the body and its concentrations are tightly regulated by a number of homeostatic biological mechanisms [1]. Despite great variations in salt and water intake, the body finely maintains serum sodium between 135 and $145 \mathrm{mmol} / \mathrm{L}$ and readings outside this range (hyponatremias or hypernatremias) are termed dysnatremias.

Serum sodium abnormalities are a common finding within the intensive care setting [2-4]. Dysnatremia can affect a number of physiological functions [5,6] and has been shown to negatively impact upon prognosis for patients in intensive care [2-4,7]. Both dysnatremia at admission and that acquired in the intensive care unit (ICU) have been shown to have a direct influence on prognosis [8]. Current studies have mostly been conducted in unselected general hospital populations and mixed ICU populations of both medical and surgical patients. There has been a single study investigating the link between dysnatremia and mortality specifically in ICU surgical patients [9].

Studies have also found that rapid correction of serum sodium levels in hypernatremic patients has a deleterious effect on survival $[10,11]$. In cardiac surgical patients, it was found that those with the greatest rate of change of serum sodium concentration were more likely to die [12]. Investigations into serum sodium fluctuations and mortality in intensive care patients are lacking. A recent study by Sakr and colleagues [9] found an independent association between sodium fluctuations and mortality, even in patients who remained within the reference range throughout their ICU stay. The association of sodium fluctuations and mortality has been validated in only one other study, in a subgroup of a pediatric population requiring externalized ventricular drains [13].

Our objective was to validate previous findings of an association between dysnatremia and both absolute sodium and sodium fluctuations with outcome in an external population of surgical patients requiring intensive care. Our primary hypothesis is that the presence of dysnatremia and fluctuations in serum sodium in both dysnatremic and normotremic patients is related to outcome in surgical ICU patients. To test this hypothesis, we performed a retrospective observational cohort study with the use of an open-source clinical database of critically ill patients. 


\section{Methods}

\subsection{Data source and study population}

Data used to conduct the observational study were obtained from the Medical Information Mart for Intensive Care (MIMIC II) clinical database. This dataset was developed by a partnership between the Massachusetts Institute of Technology, Philips Healthcare, and Beth Israel Deaconess Medical Centre (BIDMC) [14], and is compiled from information relating to patients who were hospitalized between January 2001 and December 2008. This includes all physiological data recorded in the ICU, clinical variables, investigation results (including laboratory tests), and survival outcome data. Survival outcome data were collected from social security death records after discharge.

The institutional review boards at BIDMC and the Massachusetts Institute of Technology granted ethical approval for the use of the MIMIC II database for research. A waiver for the informed consent requirement was also included in the institutional review board approval because the database does not contain protected health information.

We included consecutive surgical patients who met the inclusion criteria of age greater than 17 years and entry in the database between January 2001 and December 2008. Patients who were missing baseline sodium measurements or covariate data were excluded from the analysis.

The fluid management strategy used at the BIDMC broadly follows that outlined in the surviving sepsis campaign [15]. Typically, $30 \mathrm{~mL} / \mathrm{kg}$ of crystalloid is used for hypotension or lactatemia fluid resuscitation.

\subsection{Exposure and outcome}

Our primary exposure of interest was serum sodium fluctuation during ICU admission. The highest and lowest measured serum sodium readings were used to compute a maximum fluctuation value during admission. Patients were then categorized as those whose serum sodium went outside the reference range and those who remained within that range throughout their stay.

A secondary exposure of interest was an absolute serum sodium concentration measured to be either greater than $145 \mathrm{mmol} / \mathrm{L}$ or less than $135 \mathrm{mmol} / \mathrm{L}$ on ICU admission. Patients were categorized by severity of dysnatremia as follows: normal (135-145 mmol/L), mild hyponatremia (130-134 mmol/L), severe hyponatremia ( $<130 \mathrm{mmol} / \mathrm{L})$, mild hypernatremia (146-150 mmol/L), and severe hypernatremia (>150 mmol/L; Fig. 1).

The primary outcome was 28 -day mortality. Secondary outcomes were 1-year mortality, ICU mortality, and hospital mortality.

\subsection{Statistical analysis and modeling strategy}

Data for continuous variables are presented as medians with interquartile ranges (IQRs) and categorical variables are reported as frequencies with percentages. We assessed graphically the assumption of a normal distribution for the primary exposure variable groups using 
histograms. Univariate and multivariable logistic regressions were used to assess the association between the exposure variable and outcomes. For univariate analysis, the exposure was entered into the model alone and we report odds ratios (ORs) with 95\% confidence intervals (CIs). In an attempt to account for confounding from other parameters, we constructed multivariable logistic models. We initially included in the multivariable model all variables with a statistically significant univariate association with outcome to control for potentially clinically relevant confounding. Variables that were not associated with the outcome in the multivariable model were manually removed from the model to achieve model parsimony. Variables included in the multivariate analysis included age, sex, care unit, Simplified Acute Physiology Score II, and Sequential Organ Failure Assessment (SOFA) scores at admission, sepsis, congestive heart failure, liver disease, diabetes mellitus, and categorized creatinine value.

\subsection{Subset analysis}

We performed a subgroup analysis to assess the effect of the development of dysnatremia among patients with a normal serum sodium on ICU admission. For this analysis, we identified patients who had first measured serum sodium level between 135 and $145 \mathrm{mmol} / \mathrm{L}$ and computed the maximum absolute change in serum sodium level during the ICU stay. We computed the number of patients who developed dysnatremia during the ICU stay. We used multivariable logistic regression to assess the association between the maximum change from normal baseline and 28-day mortality.

\section{Results}

\subsection{Cohort characteristics}

A total of 8600 surgical intensive care patients were included in the final analysis. Table 1 displays the descriptive statistics of the study group that have been categorized on the basis of baseline sodium values: normotremia (135-145 mmol/L), hyponatremia ( $<135 \mathrm{mmol} / \mathrm{L})$, and hypernatremia $(>145 \mathrm{mmol} / \mathrm{L})$. A total of 7407 patients $(86 \%)$ were normotremic at baseline, and 884 (10\%) and 309 (4\%) were hyponatremic and hypernatremic, respectively. In the subgroup of patients who presented to the ICU with normal sodium values $(n=7410)$, a total of 973 patients (13\%) developed dysnatremia during the ICU stay.

There were significant differences in age, sex, and comorbidity status between normotremic and dysnatremic patients (Table 1). Patients with a dysnatremia were found to be older and more likely to be female. Hypernatremic patients had a higher SOFA score; patients with hyponatremia were more likely to be administered a vasopressor or be on ventilation. The data also show significantly higher rates of congestive heart failure and liver failure in all dysnatremic patient groups, a higher incidence of diabetes and renal failure in patients with hyponatremia, and a higher incidence of hypertension among patients with hypernatremia.

\subsection{Dysnatremia and mortality}

Overall 28-day mortality rate was $8 \%$ for all surgical patients in the ICU setting. Compared with patients with normonatremia, patients who presented with a dysnatremia had higher 28day mortality (17\% vs 7\%; $P<.0001$; Fig. 1$)$. 
Patients with hyponatremia represented $10 \%$ of the total cohort and had a 28-day mortality rate of $14 \%$. Patients with a serum sodium on admission between 130 and $134 \mathrm{mmol} / \mathrm{L}(\mathrm{n}=$ 747) had a 28-day mortality rate of $12 \%$ and those with a level lower than $130 \mathrm{mmol} / \mathrm{L}$ ( $\mathrm{n}=$ 137) had a 28 -day mortality rate of $24 \%$. Those with hypernatremia represented $4 \%$ of the total cohort and had the highest 28-day mortality rate of $25 \%$. Those with a serum sodium of 146 to $150 \mathrm{mmol} / \mathrm{L}(\mathrm{n}=259)$ had a 28 -day mortality rate of $21 \%$ and those with a level higher than $150 \mathrm{mmol} / \mathrm{L}(\mathrm{n}=50)$ had a rate of $42 \%$.

There was a statistically significant association between dysnatremia and 28-day mortality in unadjusted analysis. This association remained after multivariate adjustment for demographics, severity of illness, and comorbidities. Odds ratios corresponding to 28 -day and 1-year mortality increase with severity of dysnatremia and are presented in Fig. 2.

\subsection{Sodium fluctuations}

The median fluctuation in serum sodium concentration during ICU stay $(\mathrm{mmol} / \mathrm{L})$ was 2 (IQR, 0-5; range, 0-40). Degree of serum sodium fluctuation during the ICU stay was found to be significantly associated with both 28 -day and ICU mortality $(P<.0001$, MantelHaenszel test; Fig. 3). For each 1-mmol variation in sodium, there was a significant association with 28-day mortality (unadjusted OR, 1.15 [95\% CI, 1.13-1.18; $P<.001]$ ). After application of the multivariate model, we found an independent association between sodium fluctuation and 28-day mortality (adjusted OR, 1.10 [95\% CI, 1.08-1.12; $P<.001$ ]; Fig. 3).

\subsection{Sodium variation in normonatremic patients}

The association of sodium fluctuation and mortality was also found in patients who remained normonatremic throughout the entire length of the ICU stay $(P<.0001$, MantelHaenszel test; Fig. 4). For each 1-mmol variation in sodium, there was a significant association with 28-day mortality (unadjusted OR, 1.18 [95\% CI, 1.15-1.21; $P<.001]$ ). Using the multivariate model, we found an independent association between each 1-mmol sodium fluctuation and 28-day mortality (1.12 [95\% CI, 1.09-1.16; $P<.001])$.

\section{Discussion}

In this large observational study of adult surgical patients requiring ICU care, we found that dysnatremia is common in critically ill patients and an independent risk factor for ICU mortality. This study adds to the growing body of evidence suggesting that sodium fluctuation is an independent risk factor for ICU mortality. It validates a previous finding by Sakr and colleagues of an independent association between sodium fluctuations and mortality in patients who did not have a sodium dysregulation at any point in their ICU admission.

Sodium homeostasis is the appropriate regulation of sodium in the extracellular fluid and is crucial for the functioning of a vast number of biochemical and electrical processes within the body. Hyponatremia can result from a number of conditions including chronic heart, renal or liver dysfunction, syndrome of inappropriate antidiuretic hormone secretion, and 
Addison disease and hypothyroidism [6,16]. Hypernatremia is caused by a lack of thirst or access to free water, making the elderly and the critically ill high-risk groups $[7,17]$.

Previous studies have reported a range of different values for the prevalence of dysnatremia on admission to ICU $[2,4,7,18]$. This variation may be due to heterogeneity of individuals included in the cohorts and the different cutoffs used to define dysnatremia. Past studies have reported a higher prevalence of dysnatremia in medical and mixed ICU patients which may be a reflection of an increased severity of illness $[3,7,18,19]$. Within our cohort, $14 \%$ of patients presented to ICU with a dysnatremia and another $13 \%$ developed one during their stay.

This study is consistent with previous studies by demonstrating a close association between sodium dysregulation and mortality of the critically ill patient. [2,3,7,20]. Although we can establish association, the nature of our study does not allow determine causation. Profound hyponatremia can lead to severe neurologic complications such as cerebral oedema and herniation [21,22]. Hypernatremia presents as a range of clinical manifestations including peripheral insulin resistance, impaired hepatic gluconeogenesis and lactate clearance, various neuromuscular manifestations, and decreased ventricular contractility [5,17, 23-25]. Many studies now highlight the importance of taking into account serum sodium levels when assessing the risk of surgical ICU patients [2-4,9,12,19,26,27]. The severity of illness scoring systems Acute Physiology and Chronic Health Evaluation II [26] and Simplified Acute Physiology Score II [27] both include baseline serum sodium.

The link between sodium fluctuations and mortality in critically ill patients is poorly characterized. The association of sodium fluctuations and mortality has been shown in a large cohort of adult surgical ICU patients [9] and in pediatric ICU patients who require externalized ventriculostomy drains [13]. Our study validates the findings of an independent association between sodium fluctuations and mortality, and also the association between degree of sodium fluctuation and an increased odds of in-hospital mortality. Sakr and colleagues [9] have been the first to describe the influence of sodium fluctuation on mortality in patients who do not have a sodium dysregulation at any point during their ICU stay. Our study is the first to validate the finding of an independent association between sodium fluctuations and mortality in postsurgical ICU patients.

Current management strategies for sodium imbalance depend on the onset of the dysnatremia, volume status, and the severity of patients' symptoms. Acute hyponatremia that is eliciting moderate to severe symptoms is treated with hypertonic saline to correct serum sodium and reduce the risk of cerebral oedema. Chronic hyponatremia causing only mild symptoms is treated by the cessation of supplementary fluids and medications that may be contributing, and investigations into the cause of the dysnatremia should be pursued $[6,16]$. Hypernatremia can be corrected by the replacement of water deficits $[16,17]$. Evidence suggests that treatment should be directed by the frequent monitoring of serum sodium levels and not by the use of sodium change prediction formulae $[28,29]$.

The strengths of our study include a large cohort size using all surgical patients providing increased generalizability. We acknowledge a number of limitations that must be considered 
when interpreting these results. Although we have attempted to control for comorbid conditions and severity of illness, the possibility of unmeasured confounding remains due to the observational design of this study. For instance, dysnatremia may be secondary to aggressive diuretic use in the intensive care setting and may reflect comorbidities such as cardiac failure or hypertension. In addition, this study fails to include length of ICU stay in the analysis. Patients who spend a short amount of time in ICU could influence results by being exposed to a smaller risk of mortality and degree of sodium fluctuation. The MIMIC II database captures a huge range of clinical variables and patient information and allows for multivariable modeling. The data are from a single center, and all associations reported are dependent on variables that were measured in the ICU and included in the database. Finally, patients who were sicker may have had additional blood tests resulting in more apparent sodium fluctuations.

\section{Conclusions}

In this observational study of postoperative patients, dysnatremia is common and is associated with increased risk of mortality in postoperative patients requiring intensive care. We found that fluctuations in serum sodium were associated with an increase in 28-day mortality, even in those patients with normal serum sodium measurements during the course of the ICU stay. These data highlight the importance of dysnatremia prevention and strict control of sodium in postoperative patients.

\section{References}

1. Gennari FJ. Serum osmolality. N Engl J Med. 1984; 310(2):102-5. [PubMed: 6361557]

2. Funk G-C, Lindner G, Druml W, Metnitz B, Schwarz C, Bauer P, et al. Incidence and prognosis of dysnatremias present on ICU admission. Intensive Care Med. 2009; 36(2):304-11. [PubMed: 19847398]

3. Lindner G, Funk G-C, Schwarz C, Kneidinger N, Kaider A, Schneeweiss B, et al. Hypernatremia in the critically ill is an independent risk factor for mortality. Am J Kidney Dis. 2007; 50(6):952-7. [PubMed: 18037096]

4. Bennani S-L, Abouqal R, Zeggwagh A-A, Madani N, Abidi K, Zekraoui A, et al. Incidence, causes and prognostic factors of hyponatremia in intensive care. Rev Méd Interne. 2003; 24(4):224-9. [PubMed: 12706778]

5. Lenz K, Gössinger H, Laggner A, Druml W, Grimm G, Schneeweiss B. Influence of hypernatremichyperosmolar state on hemodynamics of patients with normal and depressed myocardial function. Crit Care Med. 1986; 14(10):913-4.

6. Adrogué HJ, Madias NE. Hyponatremia. N Engl J Med. 2000; 342(21):1581-9. [PubMed: 10824078]

7. Hoorn EJ, Betjes MGH, Weigel J, Zietse R. Hypernatraemia in critically ill patients: too little water and too much salt. Nephrol Dial Transplant. 2008; 23(5):1562-8. [PubMed: 18065827]

8. Vandergheynst F, Sakr Y, Felleiter P, Hering R, Groeneveld J, Vanhems P, et al. Incidence and prognosis of dysnatraemia in critically ill patients: analysis of a large prevalence study. Eur J Clin Invest. 2013; 43(9):933-48. [PubMed: 23869476]

9. Sakr Y, Rother S, Ferreira AMP, Ewald C, Dünisch P, Riedemmann N, et al. Fluctuations in serum sodium level are associated with an increased risk of death in surgical ICU patients. Crit Care Med. 2013; 41(1):133-42. [PubMed: 23128383]

10. Alshayeb HM, Showkat A, Babar F, Mangold T, Wall BM. Severe hypernatremia correction rate and mortality in hospitalized patients. Am J Med Sci. 2011; 341(5):356-60. [PubMed: 21358313] 
11. Mandal AK, Saklayen MG, Hillman NM, Markert RJ. Predictive factors for high mortality in hypernatremic patients. Am J Emerg Med. 1997; 15(2):130-2. [PubMed: 9115510]

12. Stelfox HT, Ahmed SB, Zygun D, Khandwala F, Laupland K. Characterization of intensive care unit acquired hyponatremia and hypernatremia following cardiac surgery. Can J Anaesth. 2010; 57(7):650-8. [PubMed: 20405264]

13. Topjian AA, Stuart A, Pabalan AA, Clair A, Kilbaugh TJ, Abend NS, et al. Greater fluctuations in serum sodium levels are associated with increased mortality in children with externalized ventriculostomy drains in a PICU. Pediatr Crit Care Med. 2014; 15(9):846-55. [PubMed: 25137551]

14. Saeed M, Villarroel M, Reisner AT, Clifford G, Lehman L-W, Moody G, et al. Multiparameter Intelligent Monitoring in Intensive Care II (MIMIC-II): a public-access intensive care unit database. Crit Care Med. 2011; 39(5):952-60. [PubMed: 21283005]

15. Dellinger RP, Levy MM, Rhodes A, Annane D, Gerlach H, Opal SM, et al. Surviving Sepsis Campaign: International Guidelines for Management of Severe Sepsis and Septic Shock, 2012. Intensive Care Med. 2013; 39(2):165-228. [PubMed: 23361625]

16. Kumar S, Berl T. Sodium. Lancet. 1998; 352(9123):220-8. [PubMed: 9683227]

17. Adrogué HJ, Madias NE. Hypernatremia. N Engl J Med. 2000; 342(20):1493-9. [PubMed: 10816188]

18. Polderman KH, Schreuder WO, Strack van Schijndel RJ, Thijs LG. Hypernatremia in the intensive care unit: an indicator of quality of care? Crit Care Med. 1999; 27(6):1105-8. [PubMed: 10397213]

19. Lindner G, Funk G-C, Lassnigg A, Mouhieddine M, Ahmad S-A, Schwarz C, et al. Intensive careacquired hypernatremia after major cardiothoracic surgery is associated with increased mortality. Intensive Care Med. 2010; 36(10):1718-23. [PubMed: 20658124]

20. Darmon M, Timsit J-F, Francais A, Nguile-Makao M, Adrie C, Cohen Y, et al. Association between hypernatraemia acquired in the ICU and mortality: a cohort study. Nephrol Dial Transplant. 2010; 25(8):2510-5. [PubMed: 20167570]

21. Sterns RH. Disorders of plasma sodium—causes, consequences, and correction. N Engl J Med. 2015; 372(1):55-65. [PubMed: 25551526]

22. Adrogué HJ, Madias NE. The challenge of hyponatremia. J Am Soc Nephrol. 2012; 23(7):1140-8. [PubMed: 22626822]

23. Bratusch-Marrain PR, DeFronzo RA. Impairment of insulin-mediated glucose metabolism by hyperosmolality in man. Diabetes. 1983; 32(11):1028-34. [PubMed: 6416909]

24. van der H Mil AHM, van Vugt JPP, Lammers GJ, Harinck HIJ. Hypernatremia from a hunger strike as a cause of osmotic myelinolysis. Neurology. 2005; 64(3):574-5. [PubMed: 15699405]

25. Kozeny GA, Murdock DK, Euler DE, Hano JE, Scanlon PJ, Bansal VK, et al. In vivo effects of acute changes in osmolality and sodium concentration on myocardial contractility. Am Heart J. 1985; 109(2):290-6. [PubMed: 3966345]

26. Knaus WA, Draper EA, Wagner DP, Zimmerman JE. APACHE II: a severity of disease classification system. Crit Care Med. 1985; 13(10):818-29. [PubMed: 3928249]

27. Le Gall J, Lemeshow S, Saulnier F. A new Simplified Acute Physiology Score (SAPS II) based on a European/North American multicenter study. JAMA. 1993; 270(24):2957-63. [PubMed: 8254858]

28. Mohmand HK, Issa D, Ahmad Z, Cappuccio JD, Kouides RW, Sterns RH. Hypertonic saline for hyponatremia: risk of inadvertent overcorrection. Clin J Am Soc Nephrol. 2007; 2(6):1110-7. [PubMed: 17913972]

29. Liamis G, Kalogirou M, Saugos V, Elisaf M. Therapeutic approach in patients with dysnatraemias. Nephrol Dial Transplant. 2006; 21(6):1564-9. [PubMed: 16449285] 


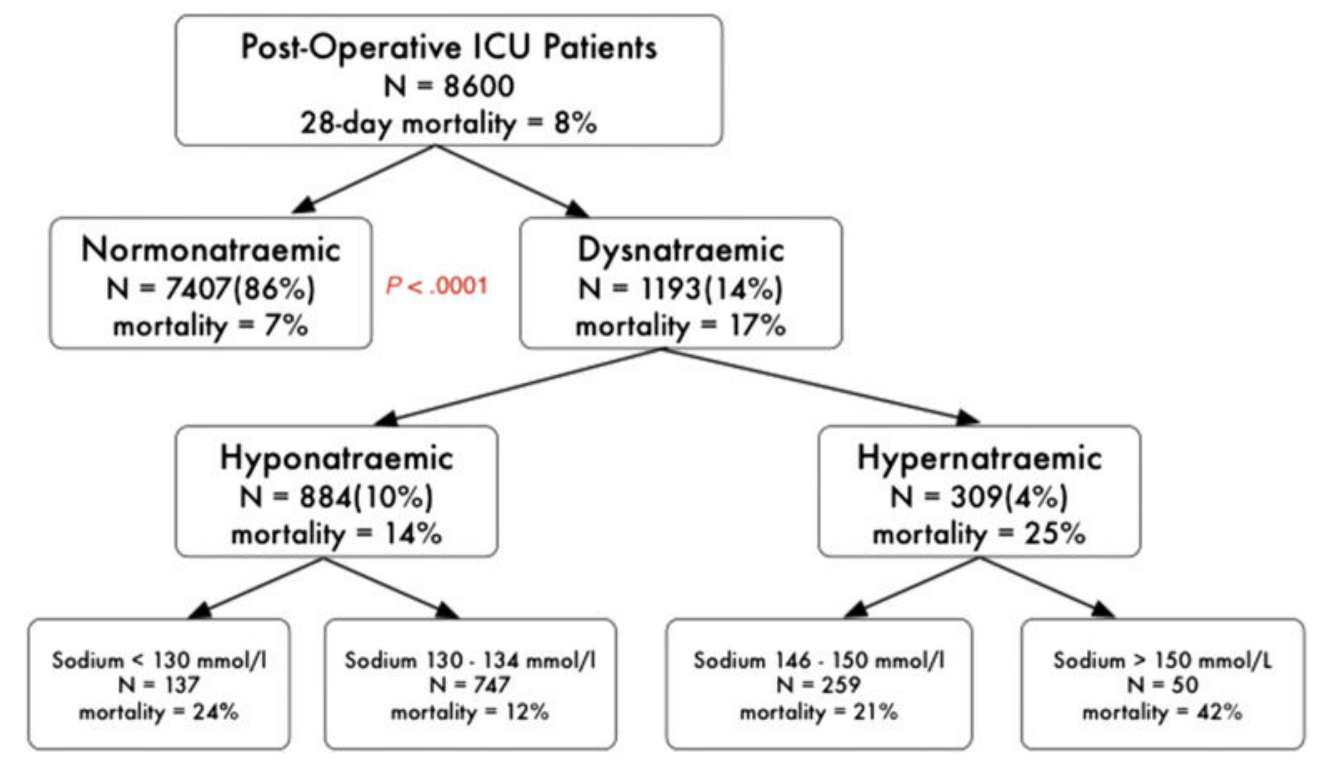

Fig. 1.

Schematic representation of the 28-day mortality of postoperative ICU patients according to serum sodium levels on ICU admission. $\chi^{2}$ Test for the difference between normotremic and dysnatremic patients. 

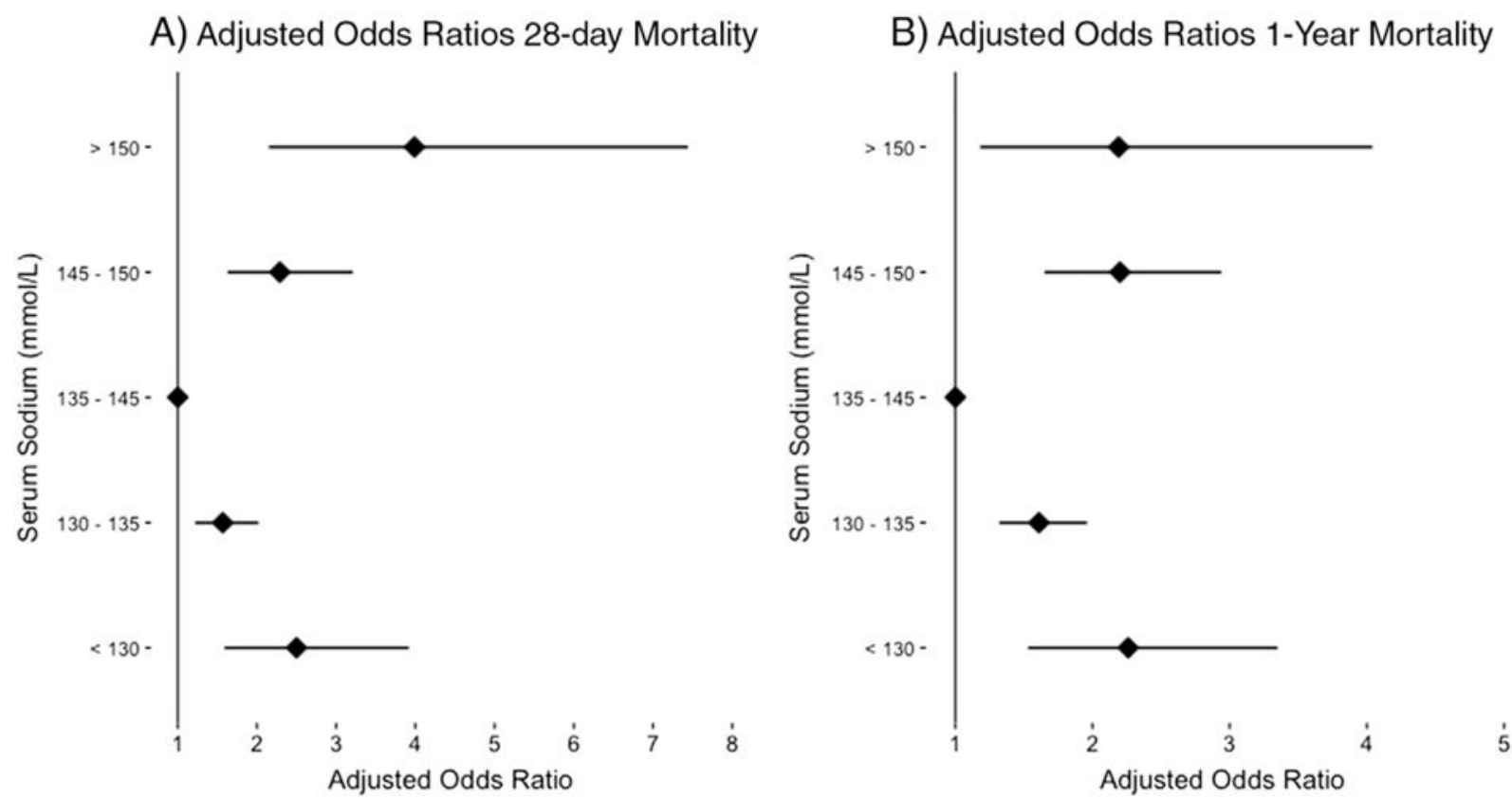

Fig. 2.

Adjusted ORs of 28-day and 1-year mortality of patients with different severities of dysnatremia. An increased risk of both 28-day and 1-year mortality in patients with dysnatremia is shown when compared with reference patients with serum sodium levels of 135 to $145 \mathrm{mmol} / \mathrm{L}$. When looking at 28-day and 1-year mortality, there is a stepwise increase in risk of mortality with increasing severity of serum sodium dysregulation. 


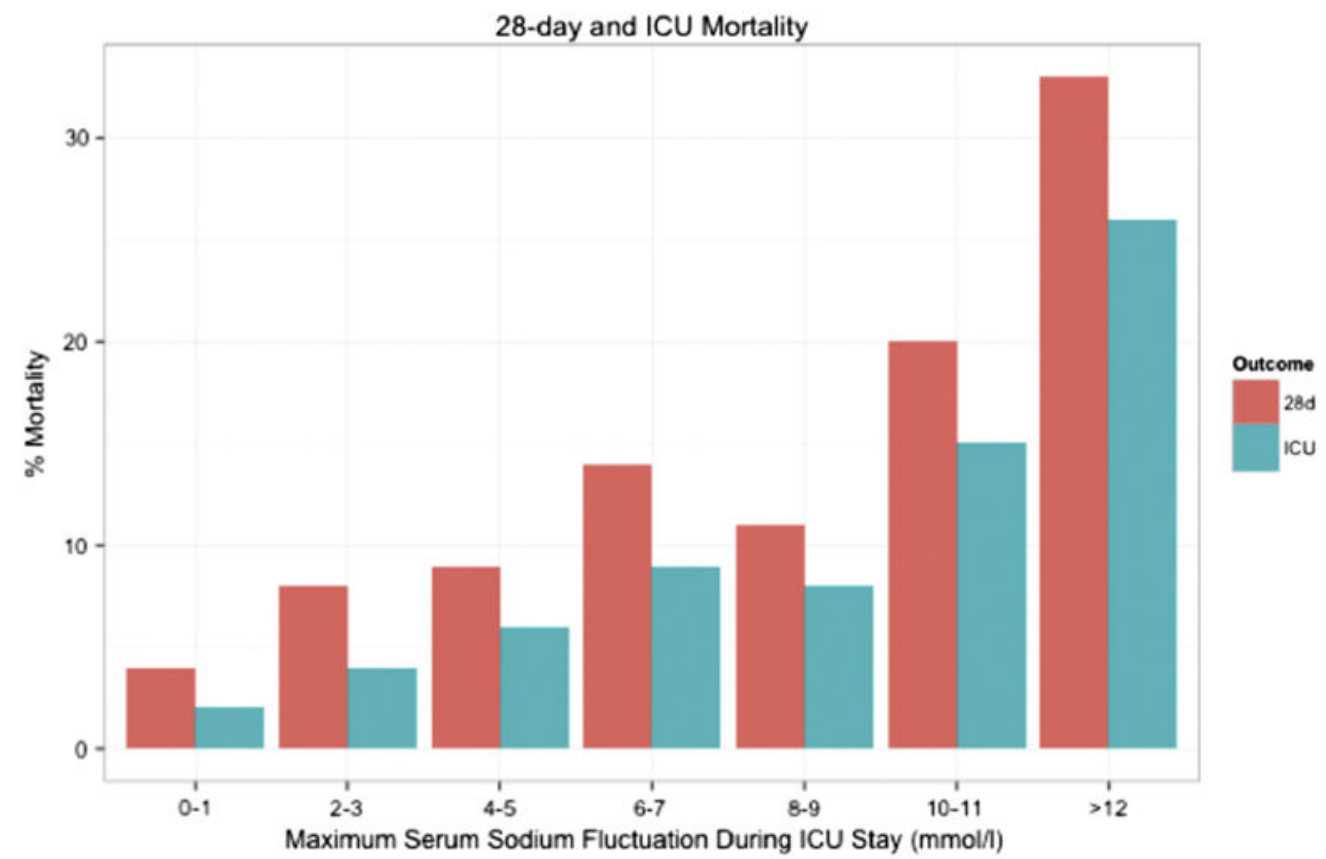

Fig. 3.

Bar chart representing maximum serum sodium fluctuations (mmol/L) and mortality $(\%)$ in patients admitted to surgical ICU $(P<.0001$; Mantel-Haenszel test). 


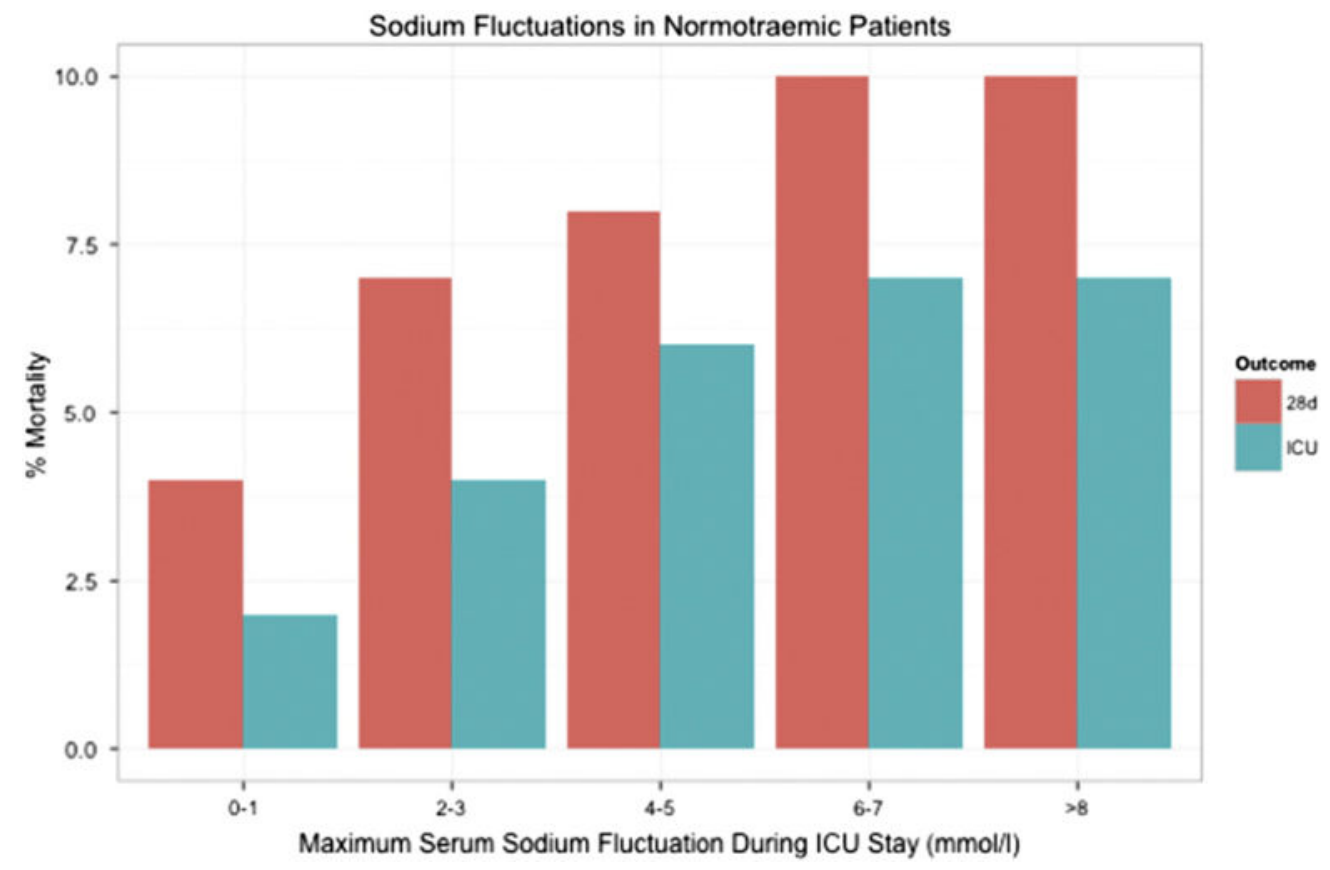

Fig. 4.

Bar chart representing maximum sodium fluctuations $(\mathrm{mmol} / \mathrm{L})$ and mortality $(\%)$ in patients who were normonatremic on admission to surgical ICU $(P<.0001$; MantelHaenszel test). 
Table 1

Characteristics of study cohort according to baseline serum sodium data

\begin{tabular}{|c|c|c|c|}
\hline Demographic & $\begin{array}{l}\text { Normotremia, } n=7407 \\
(86 \%)\end{array}$ & $\begin{array}{l}\text { Hyponatremia, } \mathrm{n}=884 \\
(10 \%)\end{array}$ & $\begin{array}{l}\text { Hyponatremia, } n=309 \\
(4 \%)\end{array}$ \\
\hline Age (y) & $65(53-77)$ & $67(55-78)^{*}$ & $69(51-80)^{*}$ \\
\hline Female, $\mathrm{n}(\%)$ & $2778(38)$ & $390(44)^{* *}$ & $151(49)^{* *}$ \\
\hline \multicolumn{4}{|l|}{ Admission type, $\mathrm{n}(\%)$} \\
\hline Elective & $2144(29)$ & $154(18)$ & $49(16)$ \\
\hline Emergency & $5023(68)$ & $682(77)$ & $252(82)$ \\
\hline Urgent & $243(3)$ & $48(5)$ & $8(3)$ \\
\hline \multicolumn{4}{|l|}{ Baseline observations } \\
\hline GCS (IQR) & $9(3-15)$ & $11(3-15)$ & $7(3-15)$ \\
\hline Systolic BP, mm Hg (IQR) & $121(107-137)$ & $120(104-136)^{*}$ & $121(107-137)$ \\
\hline \multicolumn{4}{|l|}{ Baseline severity } \\
\hline SOFA (IQR) & $7(3-9)$ & $7(3-9)$ & $8(5-11)^{* *}$ \\
\hline Vasopressor, n (\%) & $3380(46)$ & $359(41)^{*}$ & $130(42)$ \\
\hline Ventilator, n (\%) & $4968(67)$ & $487(55)^{*}$ & $212(68)$ \\
\hline \multicolumn{4}{|l|}{ Comorbidities, n (\%) } \\
\hline Congestive heart failure & $1005(14)$ & $173(20)^{* *}$ & $68(22)^{* *}$ \\
\hline Hypertension & $2459(33)$ & $310(35)$ & $85(28)^{*}$ \\
\hline Chronic pulmonary disease & $1082(15)$ & $161(18)$ & $54(17)$ \\
\hline Diabetes & $1842(25)$ & $634(28)^{*}$ & $70(23)$ \\
\hline Hypothyroid & $79(9)$ & $584(8)$ & $28(9)$ \\
\hline Renal failure & $219(3)$ & $40(5)^{* *}$ & $8(3)$ \\
\hline Liver failure & $273(4)$ & $79(9)^{* *}$ & $29(9)^{* *}$ \\
\hline Sepsis & $1074(15)$ & $213(24)$ & $118(38)$ \\
\hline \multicolumn{4}{|l|}{ Outcomes, n (\%) } \\
\hline ICU mortality & & & $408(5)$ \\
\hline Hospital mortality & & & $635(7)$ \\
\hline 28-d mortality & & & $706(8)$ \\
\hline $1-y$ mortality & & & $1286(15)$ \\
\hline
\end{tabular}

J Crit Care. Author manuscript; available in PMC 2018 April 01. 